\title{
Multiple Presynaptic Metabotropic Glutamate Receptors Modulate Excitatory and Inhibitory Synaptic Transmission in Hippocampal Area CA1
}

\author{
Robert W. Gereau IV and P. Jeffrey Conn \\ Department of Pharmacology and Program in Neuroscience, Emory University School of Medicine, Atlanta, \\ Georgia 30322
}

\begin{abstract}
The metabotropic glutamate receptors (mGluRs) have many important roles in regulation of neuronal excitability and synaptic transmission. In hippocampal area CA1, activation of mGluRs can reduce both excitatory and inhibitory synaptic transmission. The conventional view is that the presynaptic effects are mediated by L-2-amino-4-phosphonobutyric acid (L-AP4)-sensitive, or group III mGluRs (mGluR4, mGluR6, mGluR7, mGluR8). However, some studies suggest that other mGluR subtypes may also be involved in regulation of excitatory and inhibitory synaptic transmission in area CA1. We have found that two pharmacologically distinct presynaptic receptors are involved in the depression of excitatory transmission at the Schaffer collateral-CA1 synapse. Consistent with previous studies, one receptor subtype is an L-AP4-sensitive receptor that is pharmacologically similar to mGluR4 or mGluR7. However, we have found that a second mGluR subtype, which is pharmacologically similar to mGluR1 and mGluR5 (group I mGluRs), can also reduce excitatory synaptic transmission in area CA1. Analysis of effects of agonists of these two receptors on miniature EPSCs and paired-pulse facilitation suggest that both receptors are localized presynaptically. It is also shown that the mGluR that reduces transmission at inhibitory synapses in area CA1 is presynaptically locallzed, Is Insensitive to L-AP4, and is sensitive to agonlsts selective for mGluR1 and mGluR5.
\end{abstract}

[Key words: metabotropic glutamate receptor, presynaptic, synaptic transmission, excitatory amino acid, GABA, ACPD, MCPG, MAP4, MCCG, DHPG]

The metabotropic glutamate receptors (mGluRs) comprise a large family of receptors coupled to second messenger systems via GTP-binding proteins. At least eight mGluR subtypes have been cloned to date, and these receptors can be placed into three major groups based on their pharmacology, second-messenger coupling, and sequence homology (see Pin and Duvoisin, 1995, for review). Group I mGluRs (mGluR1 and mGluR5) couple primarily to phosphoinositide hydrolysis in expression systems,

Received Apr. 4, 1995; revised June 13, 1995; accepted June 20, 1995.

We thank Dr. H. Shinozaki for the gift of DCG-IV. This work was supported by NIH Grants NS-28405 and NS-31373 and a grant from the Council for Tobacco Research. R.W.G. is a predoctoral fellow of the Howard Hughes Medical Institute.

Correspondence should be addressed to P. Jeffrey Conn, Ph.D., at the above address.

Copyright (C) 1995 Society for Neuroscience $\quad 0270-6474 / 95 / 156879-11 \$ 05.00 / 0$ and are potently activated by quisqualate and selectively activaled by 3,5-dihydroxyphenylglycine (DHPG; Gereau and Conn, 1995). The group II mGluRs (mGluR2 and mGluR3) couple to inhibition of adenylyl cyclase in expression systems, and are potently and selectively activated by $\left(2 S, 1^{\prime} R, 2^{\prime} R, 3^{\prime} R\right)-2$ (2,3-dicarboxycyclopropyl) glycine (DCG-IV; Hayashi et al., 1993). The group III mGluRs (mGluR4, mGluR6, mGluR7, and mGluR8) also couple to inhibition of adenylyl cyclase in expression systems, and are most potently activated by L-AP4 and L-SOP (see Suzdak et al., 1994; Pin and Duvoisin, 1994, for reviews).

In the hippocampus, activation of mGluRs has a variety of physiological effects. These include a number of direct excitatory effects on CA1 pyramidal cells (Stratton et al., 1989; Desai and Conn, 1991; Liu et al., 1993) and different classes if inhibitory interneurons (Miles and Poncer, 1993; Desai et al., 1994; McBain et al., 1994). In addition, mGluR activation reduces both excitatory (Baskys and Malenka, 1991; Pacelli and Kelso, 1991; Desai et al., 1992, 1994) and inhibitory (Desai and Conn, 1991; Pacelli and Kelso, 1991; Desai et al., 1992, 1994; Liu et al., 1993) synaptic transmission in the hippocampus (see Glaum and Miller, 1994, for review). The conventional view has been that the depression of excitatory transmission is mediated by a group III mGluR, because mGluR autoreceptors are often sensitive to the selective group III agonist, L-AP4 (Evans et al., 1982; Lanthorn et al., 1984; Cotman et al., 1986; Baskys and Malenka, 1991). However, several studies suggest that other mGluR subtypes may also be involved. First, while L-AP4 reduces transmission at the Schaffer collateral-CA1 synapse, this effect is mimicked by quisqualate at concentrations that are inactive at the group III mGluRs (Baskys and Malenka, 1991). In addition, the depression of transmission at this synapse by 1S,3R-1-aminocyclopentane-1,3-dicarboxylic acid (1S,3R-ACPD) is antagonized by (R,S)- $\alpha$-methyl-4-carboxyphenylglycine (MCPG) (Watkins and Collingridge, 1994; but see also Chinestra et al., 1993). Because MCPG is an antagonist at mGluR1 and mGluR2, but not mGluR4 or mGluR7 (Hayashi et al., 1994; Saugstad et al., 1994), these data suggest that a receptor other than a group III mGluR may be involved in modulation of transmission at the Schaffer collateral-CA1 synapse. Thus, the nature of the mGluR subtype or subtypes that mediate depression of excitatory synaptic transmission are not entirely clear.

Previous studies have shown that activation of mGluRs also reduces transmission at GABAergic synapses onto CAl pyramidal cells (Desai et al., 1994). However, little pharmacological data is available from which one can glean information regard- 
ing the mGluR subtypes responsible for the modulation of GABAergic transmission. Furthermore, it is not known if mGluRs act presynaptically or postsynaptically to reduce IPSPs.

We now report that at least two pharmacologically distinct mGluRs are involved in modulation of excitatory synaptic transmission at the Schaffer collateral-CA1 synapse. One receptor has a pharmacology similar to the group I mGluRs, whereas the other receptor has a group III-like pharmacology. Analysis of miniature EPSCs and paired-pulse facilitation suggests that both receptors are presynaptic, but that they decrease glutamate release via different mechanisms. In addition, a group I-like receptor is involved in modulating transmission from GABAergic internęurons onto $\mathrm{C} \Lambda 1$ pyramidal cells. Analysis of spontaneous miniature IPSCs suggests that the depression of GABA transmission is likely mediated by a receptor that is presynaptically localized.

\section{Materials and Methods}

Materials. DCG-IV was generously supplied by Dr. H. Shinozaki (Tokyo Metropolitan Institute for Medical Sciences; Tokyo, Japan). IS,3RACPD, 1S,3S-ACPD, DHPG, quisqualate, L-2-amino-4-phosphonobutyric acid (L-AP4), (+)MCPG, $\alpha$-methyl-L-AP4 (MAP4), and (2S,3S,4S)2-methyl-2-(carboxycyclpropyl)glycine (MCCG) were purchased from Tocris Cookson (Bristol, UK). All other drugs were purchased from Sigma (St. Louis, MO).

Hippocampal slice preparation. The hippocampus from $100-180 \mathrm{gm}$ (30-40-d-old) male Sprague-Dawley rats was dissected on ice and 400 $\mu \mathrm{m}$ transverse slices were prepared using a Mcllwain tissue chopper. Slices were placed into oxygenated artificial cerebrospinal fluid (ACSF) containing (in mM) NaCl 124, $\mathrm{KCl} 2.5, \mathrm{CaCl}_{2} 2, \mathrm{MgSO}_{4} 1.3, \mathrm{NaH}_{2} \mathrm{PO}_{4}$ 1, glucose 10 , and $\mathrm{NaHCO}_{3} 26$, equilibrated to $\mathrm{pH} 7.4$ with $95 \% \mathrm{O}_{2}$ I $5 \% \mathrm{CO}_{2}$. After a $1 \mathrm{hr}$ recovery period, a slice was transferred to a submerged brain slice recording chamber, where it was continuously perfused with oxygenated ACSF at $1 \mathrm{ml} / \mathrm{min}$. During the recovery period, slices were generally maintained at room temperature $\left(19-22^{\circ} \mathrm{C}\right)$, except for experiments on spontaneous mEPSCs, in which the slices were maintained at approximately $25^{\circ} \mathrm{C}$.

Field potential recordings. Field potential recording electrodes were pulled on a Flaming Brown electrode puller (Sutter Instruments, San Rafael, CA) from $1.2 \mathrm{~mm}$ borosilicate glass (World Precision Instruments, Sarasota, FL) to a resistance of 1-2 M $\Omega$ with a filling solution of $2 \mathrm{M} \mathrm{NaCl}$. A bipolar tungsten stimulating electrode was placed in stratum radiatum at approximately the CA3-CA1 border for stimulation (0.1 msec; square wave) of Schaffer collateral afferents to area CA1, and the stimulus intensity was adjusted until field potential responses to afferent stimulation were less than $50 \%$ of maximal. Recording electrodes were placed in stratum radiatum of area CA1. Field potential recordings were performed at approximately $25^{\circ} \mathrm{C}$ using an Axoclamp $2 \mathrm{~A}$ (Axon Instruments, Foster City, CA) in bridge mode.

Intracellular recordings. For recording inhibitory postsynaptic potentials, sharp microelectrodes were fabricated from $1.2 \mathrm{~mm}$ borosilicate glass (WPI) using a Flaming Brown electrode puller. Electrodes were filled with $2 \mathrm{M} \mathrm{KMeSO}_{4}$, and had resistances from 150-250 M 2 . In experiments in which monosynaptically evoked IPSPs were isolated, the stimulating electrode was placed close to the recording site, and the bathing ACSI contained $1 \mathrm{~mm}$ kynurenate to block fast glutamatergic transmission. Blockade of excitatory transmission was confirmed by the absence of a depolarizing synaptic potential following afferent stimulation. Stimulus intensity was adjusted to evoke a response $<50 \%$ of maximal. Cells were manually "clamped" at the original resting membrane potential by current injection for the duration of the experiment.

Whole-cell patch clamp recordings. Whole-cell patch clamp recordings were obtained from CAl pyramidal cells using a Warner Instruments Corp (Hamden CT) patch clamp model PC-501A using the "blind" patch technique as described by Blanton et al. (1989). Patch clamp recordings were performed at room temperature, except for experiments measuring mEPSCs, for which the temperature was elevated to approximately $25^{\circ} \mathrm{C}$. This increase in temperature substantially increased the frequency of spontaneous events. Patch electrodes were fabricated from $1.5 \mathrm{~mm}$ borosilicate glass (World Precision Instruments, Sarasota, FL) to a resistance of $2-7 \mathrm{M} \Omega$ with a filling solution that contained (in mM) HEPES 40, Gluconic acid 100, EGTA 0.6, GTP 0.3, ATP 2, $\mathrm{MgCl}_{2} 5, \mathrm{pH}$ to 7.4 with $50 \% \mathrm{CsOH}$ for EPSCs. The electrode solution for recording IPSCs was identical except that $\mathrm{CsCl}$ was substituted for the gluconic acid. Cells with a series resistance of greater than $25 \mathrm{M} \Omega$ were discarded, and no series resistance compensation was used. ACSF for EPSC recordings contained $100 \mu \mathrm{M}$ picrotoxin, and the Schaffer collateral pathway was cut at the CA3/CA1 border to reduce the impact of recurrent excitatory circuits on CA1 recordings. Stimuli were delivered to the Schaffer collateral pathway at a rate of $1 / 30 \mathrm{sec}$. For mFPSC and mIPSC recordings, ACSF contained TTX (500 nM). In mIPSC recordings, fast glutamatergic transmission was blocked by the inclusion of kynurenate $(1 \mathrm{mM})$ in the bathing ACSF.

$\Lambda$ gonists and antagonists were dissolved in ACSF at $10 \times$ final concentration and added to the perfusion medium using a Sage syringe pump. All agonist applications used in computation of mean effects were 10 min in duration to allow equilibration with the drug with the tissue. Exceptions include picrotoxin, TTX, and kynurenate, which were diluted to final concentration in the bathing ACSF and applied for the duration of the experiment when used. Kynurenate was dissolved in 1 $\mathrm{N} \mathrm{NaOH}$ before being diluted to the final concentration in ACSF. The $\mathrm{pH}$ of the ACSF was then adjusted to 7.4 using $12 \mathrm{~N} \mathrm{HCl}$. MCPG, MAP4, MCCG, L-AP4, 1S,3S-ACPD, 1S,3R-ACPD, and quisqualate were all dissolved at $\geq 100 \times$ final concentration in $0.1 \mathrm{~N} \mathrm{NaOH}$ before being diluted to $10 \times$ final concentration with ACSF.

Evoked potential and evoked current data were acquired and analyzed using pClamp software (Axon Insturuments). Miniature EPSC and IPSC data were collected using Axotape softwarc (Axon Insturments). Data were digitized at $5 \mathrm{KHz}$ and filtered at $0.5-1 \mathrm{KHz}$ and written directly to a computer hard drive. mEPSC and MIPSC analysis was carried out using the $\mathrm{N}$ spontaneous events analysis software, generously provided by Dr. Stephen Traynelis (Emory University, Department of Pharmacology).

\section{Results}

Agonist pharmacology of the depression of synaptic transmission at the Schaffer collateral-CAl synapse

Previous studies suggest that a group III mGluR may be involved in regulation of excitatory synaptic transmission at the Schaffer collateral-CA1 synapse. However, this hypothesis has not been rigorously tested. Previous studies suggest that 3,5dihydroxyphenylglycine (DHPG) is a highly selective agonist for the group I mGluRs (mGluR1 and mGluR5; Schoepp et al., 1994; Gereau and Conn, 1995). We and others have also shown that (2S, $\left.1^{\prime} \mathrm{R}, 2^{\prime} \mathrm{R}, 3^{\prime} \mathrm{R}\right)$-2-(2,3-dicarboxycyclopropyl)glycine (DCGIV) is highly selective for the group II mGluRs (mGluR2 and mGluR3; Hayashi et al., 1992; Gereau and Conn, 1995), and much work suggests that L-AP4 has a high degree of selectivity for the group III mGluRs (mGluRs 4, 6, 7, and 8; see Suzdak et al., 1994, for review). We tested the hypothesis that the mGluR autoreceptor at the Schaffer collateral-CA1 synapse belongs to group III by examining the effects of these group-selective agonists on crokcd excitatory postsynaptic currents (EPSCs) recorded from CA1 pyramidal cells in response to stimulation of Schaffer collaterals.

In agreement with previous reports, we found that the group IIIselective agonist D,L-AP4 ( $1 \mathrm{mM})$ induced a reversible depression of EPSCs in area CA1 (Fig. 1). However, we also found that the group I-selective agonist, DHPG $(100 \mu \mathrm{M})$, induced a depression of EPSCs. The group II-selective agonist, DCG-IV, had no effect on the amplitude of evoked EPSCs (Fig. 1). The finding that both DHPG and L-AP4 inhibit EPSCs suggests that this response could not be mediated solely by a group III mGluR. We also determined the rank order of potency of a variety of mGluR agonists at reducing field excitatory postsynaptic potentials (fEPSPs) in area CA1. The agonist rank order of potency for depression of fEPSPs was DHPG $\geq 1 S, 3 R-A C P D>1 S, 3 S-A C P D \geq L-A P 4>$ L-SOP (Fig. 2). This rank order of agonist potency differs from that of the group III mGluRs or any of the mGluRs cloned to date (see Pin and Duvoisin, 1994, for review). 
A

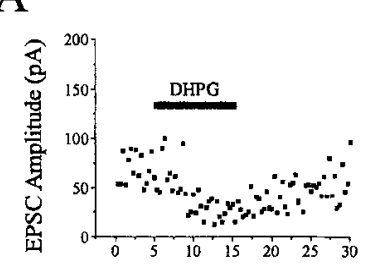

B

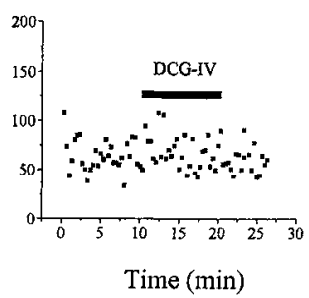

C
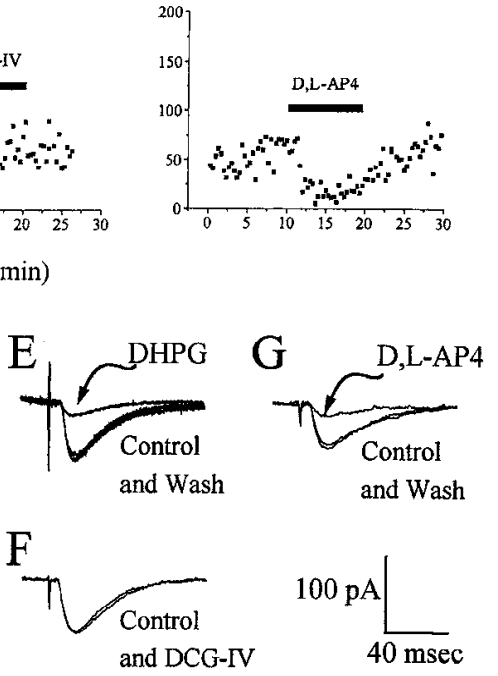

Figure I. Agonists selective for group I and group III mGluRs, but not group II mGluRs, reduce EPSCs at the Schaffer collateral-CA1 synapse. $A-C$, Plots of EPSC amplitude over time showing the effect of application of the group I-selective agonist, DHPG $(A$; $100 \mu \mathrm{M})$, the group II-selective agonist, DCG-IV $(B ; 1 \mu \mathrm{M})$, and the group IIIselective agonist, D,L-AP4 (1 mM). $D$, Mean data \pm SEM of four to seven experiments in each group. ${ }^{*} p<0.05$, ANOVA. $E$ and $F$, Traces taken from representative experiments showing the effect of DHPG, DCG-IV and D,LAP4 on evoked EPSCs. Each trace is an average of five events recorded immediately prior to drug addition, after $10 \mathrm{~min}$ in agonist, and after at least 10 min of washout.
These data could be interpreted in one of two ways. First, these data could suggest that both group I and group III mGluRs are involved in regulating transmission at the Schaffer collateral-CA1 synapse. This would be consistent with the effects of DHPG and L-AP4, as well as the rank order of agonist potencies. However, it is also possible that this response is mediated by a single mGluR subytpe that is pharmacologically distinct from any of the mGluRs that have been cloned to date. Thus, we performed a series of studies to differentiate between these two possibilities.

\section{Antagonist profiles suggest that multiple mGluRs modulate excitatory synaptic transmission}

If the effects of DHPG and L-AP4 are mediated by the same receptor, then the depression of transmission induced by the two agonists should be similarly blocked by an antagonist of the receptor. If, however, the effects of DHPG and L-AP4 are mediated by activation of two distinct receptors, then an antagonist

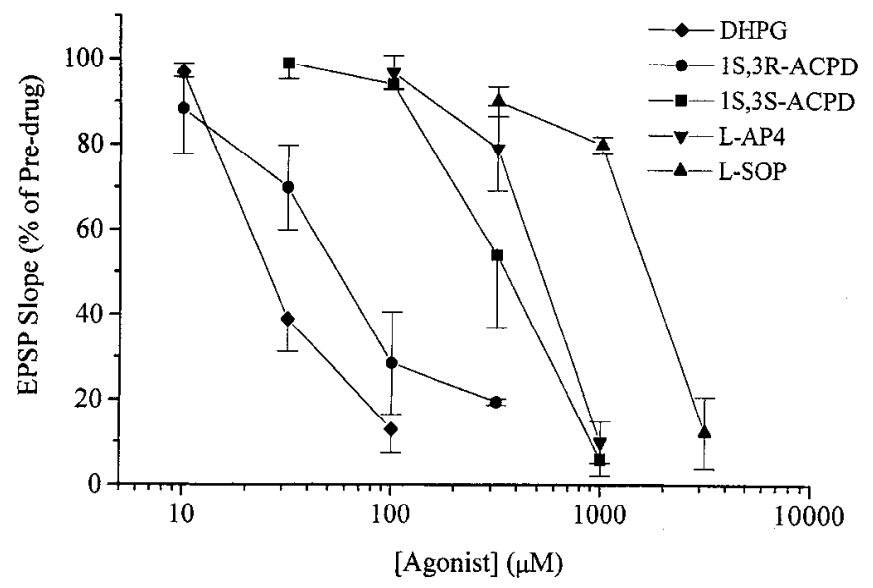

Figure 2. Rank order of agonist potencies for mGluR-mediated depression of fEPSPs. Shown is the mean \pm SEM depression of field EPSP slope induced by increasing concentrations of several mGluR agonists. Data are expressed as percent of the predrug EPSP slope. Only a single concentration of a given agonist was applied to each slice, and the effects of different concentrations were averaged across experiments. $N=3-5$ for each point. may block the effects of one agonist, but not the other. Therefore, in order to test the hypothesis that the depression of synaptic transmission at the Schaffer collateral-CA1 synapse induced by DHPG is mediated by a receptor other than the L-AP4-sensitive receptor at this synapse, we tested the ability of several mGluR antagonists to block the effects of submaximal concentrations of DHPG and L-AP4 on fEPSPs in area CA1.

Previous studies have shown that $(+) \mathrm{MCPG}$ is an antagonist of at least two mGluR subtypes: mGluR1 and mGluR2, while it is inactive at mGluR4 and mGluR7 (Hayashi et al., 1994; Saugstad et al., 1994). Of these receptors, DHPG activates only mGluR1 and mGluR5 (Gereau and Conn, 1995), whereas L-AP4 activates only the group III mGluRs, of which only mGluR4 and mGluR7 are expressed in the hippocampus (see Testa et al., 1994, for review; Okamoto et al., 1994; Saugstad et al., 1994). We tested the ability of (+)MCPG $(500 \mu \mathrm{M})$ to block the depression of fEPSPs induced by submaximal concentrations of DHPG $(31.6 \mu \mathrm{M})$ and L-AP4 $(316-500 \mu \mathrm{M})$. Interestingly, MCPG markedly inhibited DHPG-induced depression of fEPSPs ( $p<0.01 ; N=4$; Fig. 3 ). In contrast, the depression of fEPSPs induced by two different concentrations of L-AP4 was completely unaffected by inclusion of $(+)$ MCPG in the ACSF ( $p>$ $0.05, N=4$; Fig. 3).

Two novel mGluR antagonists, $\alpha$-methyl-CCG1 (MCCG) and $\alpha$-methyl-L-AP4 (MAP4) have recently been described, and these drugs exhibit some selectivity for antagonism of depression of synaptic responses in the spinal cord by trans-ACPD and L-AP4, respectively (Jane el al., 1994), and reduction of GABAergic transmission in the thalamus by L-CCGl and L-AP4, respectively (Salt and Eaton, 1995). It is suggested that MCCG is an antagonist for the group II mGluRs because it blocks the effects of L-CCG1, highly potent group II agonist, and that MAP4 is a selective antagonist for group III mGluRs, because it selectively blocks the effects of L-AP4, the most potent agonist at the group III mGluRs (Jane et al., 1994; Salt and Eaton, 1995). However, the effects of these compounds on the cloned mGluRs are not yet known. At concentrations that completely inhibited the effects of trans-ACPD in spinal cord, MCCG $(250 \mu \mathrm{M})$ had no effect on the depression of fEPSPs induced by either DHPG $(31.6 \mu \mathrm{M})$ or L-AP4 $(500 \mu \mathrm{M})$. Simi- 
Figure 3. Antagonist profile for the inhibition of fEPSPs by DHPG and L-AP4. A, Representative traces showing the depression of fEPSPs induced by DHPG $(31.6 \mu \mathrm{M})$ or L-AP4 $(500 \mu \mathrm{M})$ in the absence (control) and presence of $(+)$ MCPG $(500 \mu \mathrm{M})$, MAP4 $(500 \mu \mathrm{M})$, or MCCG $(250 \mu \mathrm{M})$. Traces shown are an average of five individual events recorded immediately before agonist addition and after $10 \mathrm{~min}$ in agonist (indicated by + ). Note the selective antagonism of DHPG-, but not L-AP4-induced depression of fEPSPs by (+)MCPG. Neither MAP4 nor MCCG had any significant effect on the depression of EPSPs induced by DHPG or L-AP4 ( $N=4$ for each condition). Antagonists were always applied at least 5 min before addition of agonists, as shown in panel $B$. $B$, Time course from a representative experiment showing that (+)MCPG reversibly blocks the DHPG-induced depression of excitatory synaptic transmission. $C$, Mean $\pm \mathrm{SEM}$ data showing (+)MCPG-mediated blockade of depression of fEPSPs by DHPG $(31.6 \mu \mathrm{M})$ and the lack of effect of $(+) \mathrm{MCPG}$ on the depression of fEPSPs by two concentrations of L-AP4 (316 $\mu \mathrm{M}, 500 \mu \mathrm{M}) . N=4$ for each condition. ${ }^{*} p<0.05, t$ test.
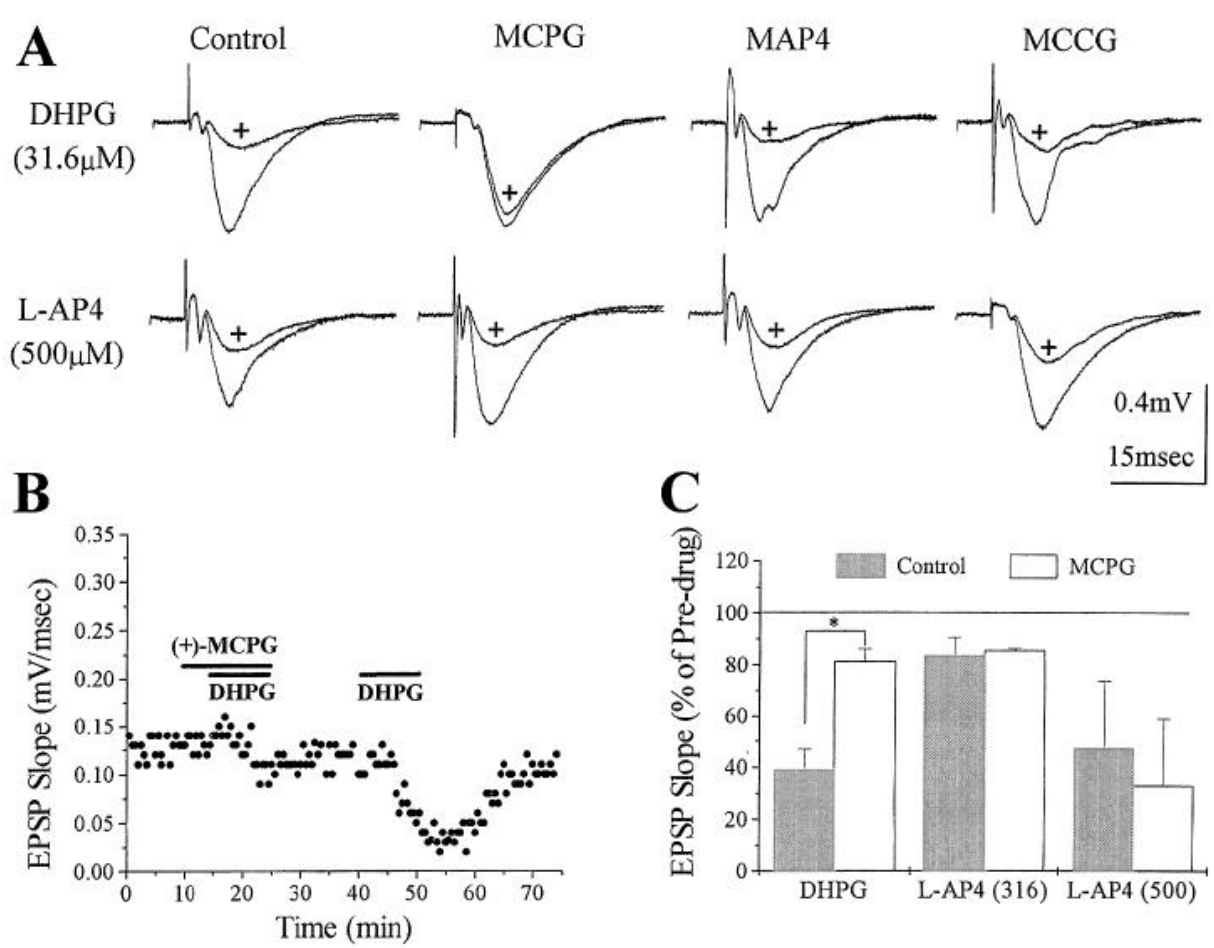

larly, at concentrations that completely blocked the effects of L-AP4 in the spinal cord, MAP4 $(500 \mu \mathrm{M})$ had no effect on the fEPSP depression induced by DHPG or L-AP4 (Fig. 3).

\section{Distinct presynaptic loci for inhibition of excitatory synaptic transmission}

Previous studies suggest that the nonselective mGluR agonist trans-ACPD may reduce excitatory synaptic transmission at the Schaffer collateral-CA1 synapse by a presynaptic mechanism, because trans-ACPD has no effect on AMPA-evoked currents in CA1 pyramidal cells, but alters paired-pulse facilitation at this synapse (Baskys and Malenka, 1991). However, the locus of the L-AP4 and DHPG-induced depression of excitatory synaptic transmission is unknown. In order to determine whether L-AP4 and DHPG reduce transmission at the Schaffer collateral-CA1 synapse by presynaptic mechanisms, the effects of maximal concentrations of these drugs on frequency and amplitude of spontaneous miniature EPSCs (mEPSCs) was determined.

Whole-cell recordings were made from CAl pyramidal cells in the presence of TTX (500 nM) to block action potential-dependent release events, and picrotoxin $(100 \mu \mathrm{M})$ to block GA$\mathrm{BA}_{\mathrm{A}}$-mediated synaptic currents. All remaining synaptic currents were completely blocked by inclusion of the ionotropic glutamate receptor antagonist, kynurenate (1 mM; see Fig. 5A). L-AP4 (1 mM) significantly reduced the frequency of mEPSCs in area $\mathrm{CA} 1$, but had no effect on the amplitude distribution of mEPSCs, suggesting that L-AP4 acts presynaptically to reduce glutamate release (Fig. 4; Table 1). DHPG (100 $\mu \mathrm{M})$ did not significantly reduce mEPSC frequency or amplitude, suggesting that DHPG also acts presynaptically to reduce transmission, but likely through a different mechanism than the L-AP4-sensitive receptor (Fig. 5; Table 1). Neither L-AP4 nor DHPG significantly altered the rise time or decay kinetics of mEPSCs (Table 1), suggesting that these agonists did not significantly alter space clamp. Although we did not detect any change in mEPSC amplitude in response to L-AP4 or DHPG, manipulations that alter postsynaptic responses did result in discernable effects on mEPSC amplitude. Thus, by changing the holding potential from -90 to $-40 \mathrm{mV}$, we were able to detect large shifts in the amplitude distribution of mEPSCs, while the frequency was unaffected $(N=3$; Fig. $4 F, G)$. Similar results were observed in response to low doses of the selective nonNMDA ionotropic glutamate receptor antagonist, 6,7-dinitroquinoxaline-2,3-dione (DNQX; $1 \mu \mathrm{M}$, not shown). The finding that manipulations known to alter EPSCs by a postsynaptic mechanism reduce mEPSC amplitude but not frequency suggests that our methods are sensitive to postsynaptic changes. Therefore, the lack of effect of the mGluR agonists on mEPSC amplitude are consistent with a presynaptic site of action of L-AP4 and DHPG, rather than a postsynaptic antagonism. The finding that L-AP4 has no postsynaptic antagonist action is consistent with previous findings that L-AP4 at concentrations up to $1 \mathrm{~mm}$ does not block depolarizations induced by exogenously applied glutamatergic agonists (Evans et al., 1982).

Another method that is often used to determine whether a compound reduces synaptic transmission by a presynaptic or postsynaptic mechanism is measurement of paired-pulse facilitation. Agents that act presynaptically to reduce transmission generally potentiate paired-pulse facilitation, whereas agents that act postsynaptically induce a proportional decrease in the first and second responses in a paired-pulse facilitation protocol and therefore have no effect on paired-pulse facilitation. In agreement with the results of the mEPSC experiments, we found that both L-AP4 (1 mM; $N=3)$ and DHPG $(100 \mu \mathrm{M} ; N=3)$ altered paired-pulse facilitation at this synapse, consistent with a presynaptic site of action. In contrast, DNQX, $(1 \mu \mathrm{M})$ reduced the first and second fEPSPs proportionally, consistent with its known postsynaptic site of action (Fig. 6). 
A
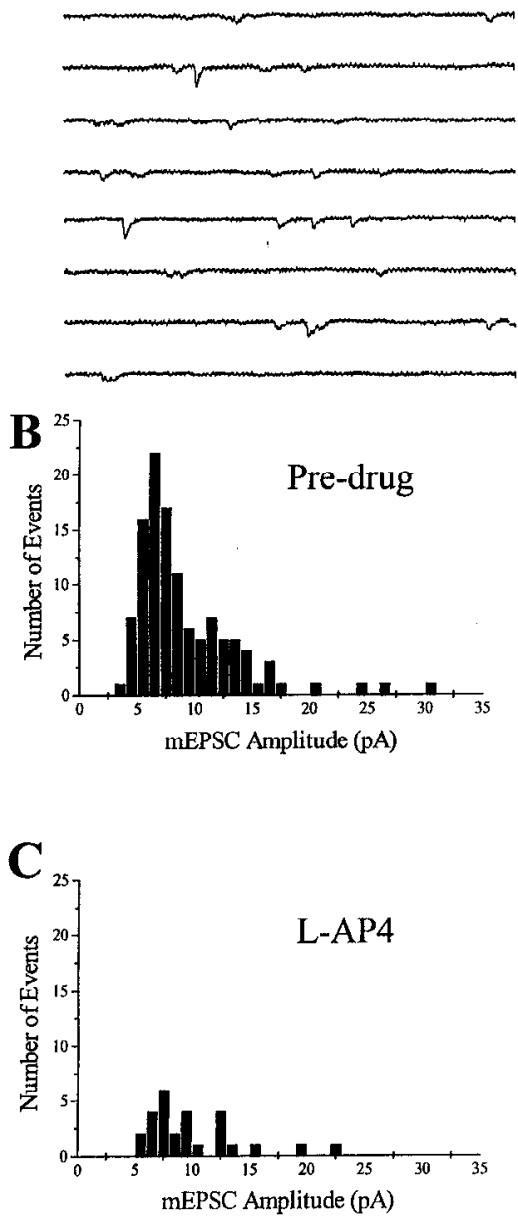

L-AP4

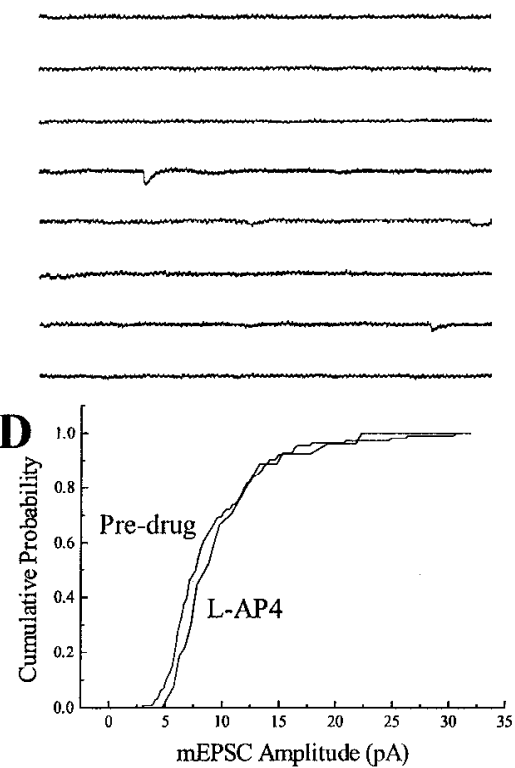

$\mathbf{E}$

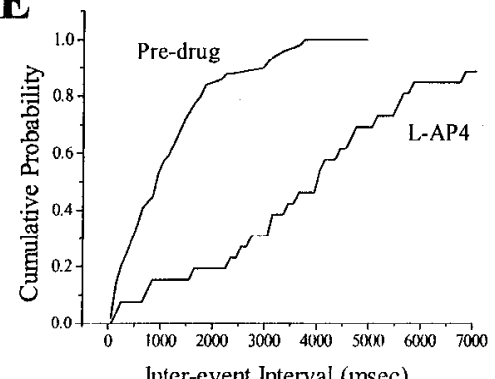

Wash

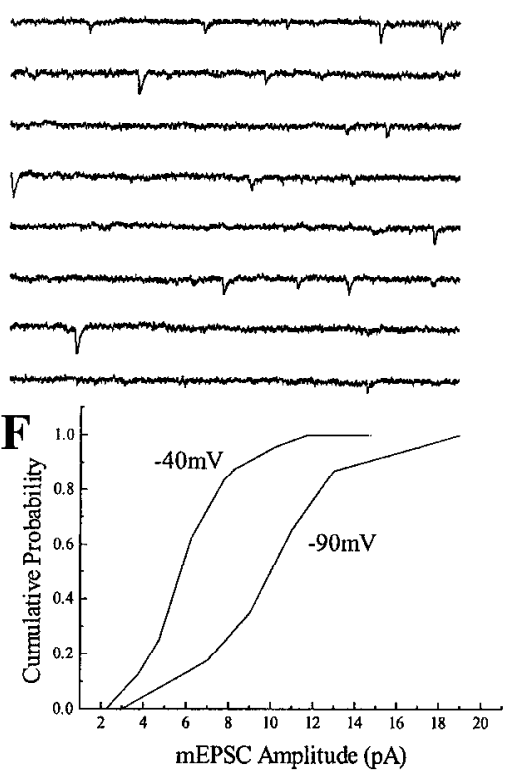

G
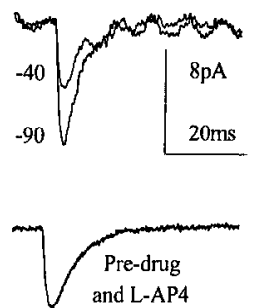

Figure 4. L-AP4 reduces the frequency but not the amplitude of spontaneous miniature EPSCs. mEPSCs were recorded from CA1 pyramidal cells in the presence of TTX $(500 \mathrm{nM})$ and picrotoxin $(100 \mu \mathrm{M})$. A, Continuous records taken immediately prior to addition of L-AP4 (predrug) and after $10 \mathrm{~min}$ in L-AP4 $(1 \mathrm{mM})$. Traces are $1.5 \mathrm{sec}$ in duration and are separated by $40 \mathrm{pA} . B$ and $C$, Amplitude histograms of mEPSCs recorded for $2 \mathrm{~min}$ before drug addition $(B)$ and after $10 \mathrm{~min}$ in the presence of L-AP4 $(1 \mathrm{~mm}, C)$. All events were measured and sorted into 1 pA bins. $D$, Cumulative frequency plot demonstrating the lack of effect of L-AP4 on mEPSC amplitude (Kolmogorov-Smirnov test; $p>0.01$ ). $E$, Cumulative probability plot demonstrating the significant effect of L-AP4 on interevent interval (Kolmogorov-Smirnov test, $p<0.0001$ ). Similar results werc observed in three separate experiments. $F$, Control experiment demonstrating that a change in postsynaptic EPSC driving force results in a detectable change in mEPSC amplitude (Kolmogorov-Smirnov test, $p<0.0001$ ). $G$, Overlayed average EPSCs of all events showing the effect of a change in holding potential on mEPSC amplitude and the lack of effect of L-AP4 on mEPSC amplitude.

The effects on mEPSCs and paired-pulse facilitation are consistent with presynaptic sites of action for L-AP4 and DHPG. L-AP4 appears to be acting, at least in part, by decreasing the release probability. However, since DHPG has no effect on either frequency or amplitude of mEPSCs, the mechanism of action of DHPG is less clear. Several studies have shown that mGluR activation can inhibit voltage-sensitive calcium channels
(Lester and Jahr, 1990; Swartz and Bean, 1992; Trombley and Westbrook, 1992; Sahara and Westbrook, 1993; Swartz et al., 1993; Stefani et al., 1994). Since presynaptic calcium channels are voltage dependent and mEPSCs are not dependent on action potential firing, it is possible that agonists that decrease synaptic transmission by inhibitiing calcium channel conductance would not decrease mEPSC frequency. We tested this possibility under

Table 1. Effect of DIIPG and L-AP4 on mEPSC properties

\begin{tabular}{lrrrr} 
& \multicolumn{1}{c}{ Control } & \multicolumn{1}{c}{ L-AP4 } & \multicolumn{1}{c}{ Control } & \multicolumn{1}{c}{ DHPG } \\
\hline $\begin{array}{l}\text { mEPSC amplitude } \\
\quad(\mathrm{pA})\end{array}$ & $7.4 \pm 0.3$ & $7.2 \pm 1.2$ & $7.2 \pm 0.3$ & $7.0 \pm 0.9$ \\
$\begin{array}{l}\text { mEPSC 10-90\% rise } \\
\quad \text { time (msec) }\end{array}$ & $4.5 \pm 0.4$ & $4.4 \pm 0.3$ & $4.3 \pm 0.4$ & $4.3 \pm 0.4$ \\
mEPSC $\tau$ decay (msec) & $12.9 \pm 0.5$ & $13.7 \pm 0.7$ & $12.4 \pm 1.4$ & $11.0 \pm 1.3$ \\
\hline
\end{tabular}


$\mathbf{A}$

Pre-Drug

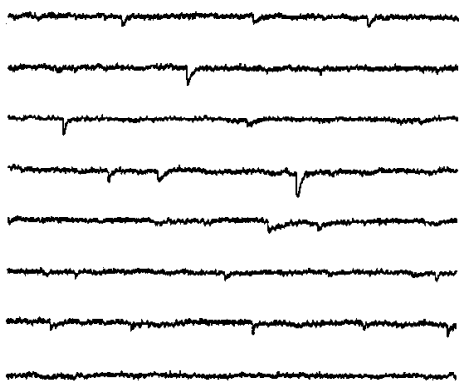

B

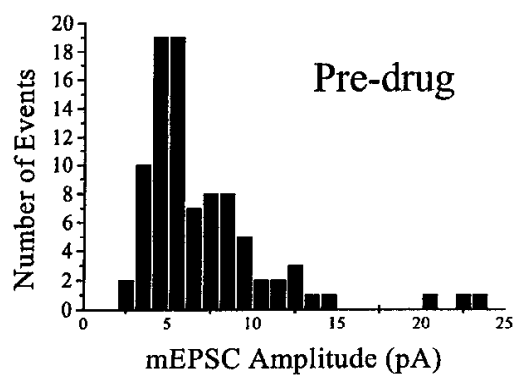

C

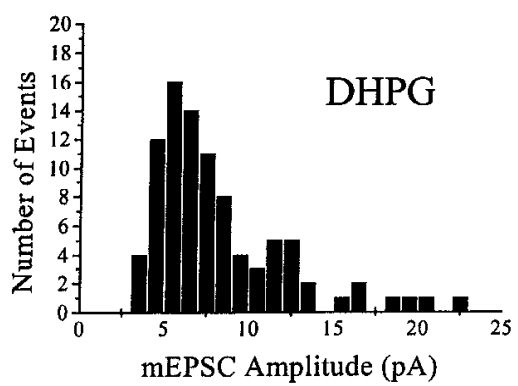

DHPG
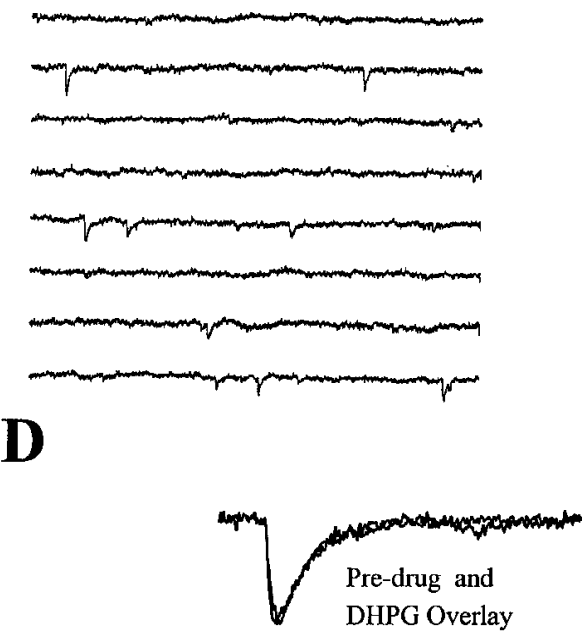

E

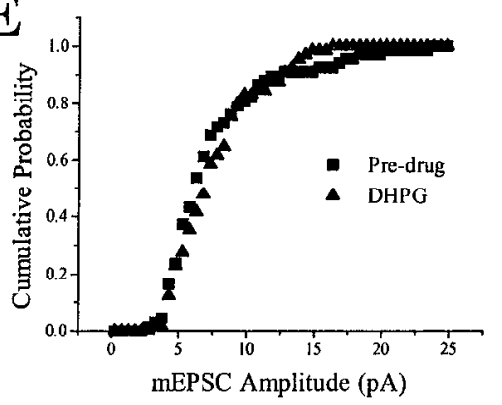

Kynurenate

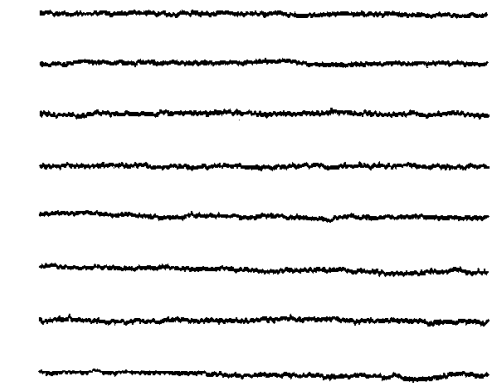

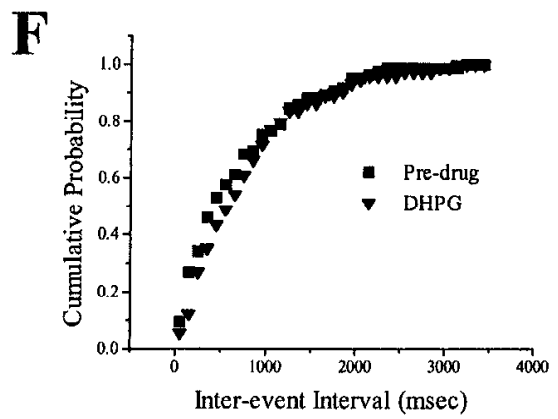

Figure 5. DHPG has no effect on frequency or amplitude of spontaneous miniature EPSCs. mEPSCs were recorded from CA1 pyramidal cells in the presence of TTX $(500 \mathrm{nM})$ and picrotoxin $(100 \mu \mathrm{M}) . A$, Continuous records taken immediately prior to addition of DHPG (predrug), after 10 $\min$ in DHPG $(100 \mu \mathrm{M})$, and in the presence of kynurenate $(1 \mathrm{~mm})$. Traces are $1.5 \mathrm{sec}$ in duration and are separated by $40 \mathrm{pA}$. $B$ and $C$, mEPSC amplitude histograms. mEPSCs were recorded for $1 \mathrm{~min}$ prior to drug addition $(B)$ and after $10 \mathrm{~min}$ in DHPG $(C)$. All events were measured and sorted into $1 \mathrm{pA}$ bins. Number of events in the $60 \mathrm{sec}$ prior to DHPG addition $=90$, number of events in $60 \mathrm{sec}$ after 10 min in DHPG $=91 . D$, Overlayed averages of all mEPSCs recorded during the time periods shown in $B$ and $C$ demonstrating the lack of effect of DHPG on mEPSC amplitude and kinetics. $E$, Cumulative probability plot demonstrating the lack of effect of DHPG on mEPSC amplitude (Kolmogorov-Smirnov test; $p>0.01$ ). $F$, Cumulative probability plot showng the lack of effect of DHPG on interevent interval (Kolmogorov-Smirnov test; $p>0.01$ ). Similar results were observed in three separate experiments.

the conditions used for measurement of the effect of DHPG on mEPSCs by determining the effect of the calcium channel blocker cadmium on mEPSCs and evoked fEPSPs. Consistent with a previous report (Parfitt and Madison, 1993), we found that $1 \mathrm{mM}$ $\mathrm{CdCl}_{2}$ completely blocked evoked fEPSPs but had no effect on the frequency or amplitude of mEPSCs (Fig. 7).

\section{A group I mGluR modulates GABAergic transmission in area CAl}

Previous studies have shown that $1 \mathrm{~S}, 3 \mathrm{R}-\mathrm{ACPD}$ can reduce GABA-mediated IPSPs in area CA1 (Desai and Conn, 1991; Pacelli and Kelso, 1991; Desai et al., 1992, 1994; Liu et al., 1993). This is mediated by a combination of reducing transmission at excitatory synapses onto interneurons and inhibitory synapses onto pyramidal cells (Desai et al., 1994). While it is clear from these studies that $\mathrm{mGluR}$ activation inhibits transmission at GABAergic synapses, the pharmacology of the receptor mediating this response, as well as its site of action, are unknown.
In order to determine if multiple mGluRs could also regulate GABAergic transmission in area CA1, the effects of the groupselective agonists DHPG, DCG-IV, and I,-AP4 on monosynaptically evoked IPSPs were determined.

As was the case for excitatory transmission, the group I-selective agonist, DHPG $(100 \mu \mathrm{M})$ was found to reduce monosynaptic IPSPs in area CA1 (Fig. 8). However, both the group IIselective agonist, DCG-IV $(1 \mu \mathrm{M})$, and the group III-selective agonist, L-AP4 (1 mM), were without effect on monosynaptic IPSP amplitude. This finding suggests that transmission at G $\Lambda$ BAergic synapses in area CA1 is regulated by a group I-like mGluR. Consistent with this, we found that quisqualate $(10 \mu \mathrm{M})$, another potent and relatively selective group I mGluR agonist, also reduced the amplitude of monosynaptic IPSPs in area CA1 (Fig. 8). As was the case for modulation of excitatory synaptic transmission, the depression of monosynaptic IPSPs induced by DHPG $(100 \mu \mathrm{M})$ was completely inhibited by inclusion of 500 $\mu \mathrm{M}(+) \mathrm{MCPG}$ in the bathing ACSF (Fig. 9). 
$\mathbf{A}$

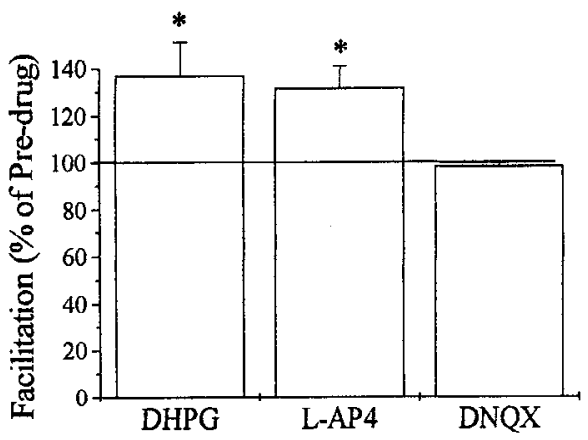

B

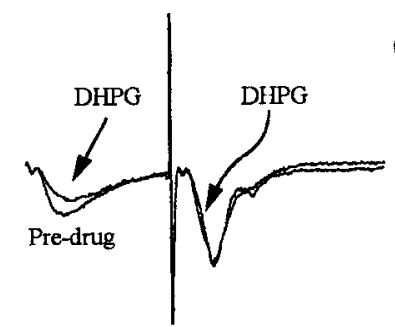

C

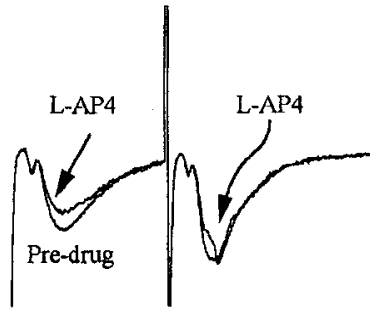

D

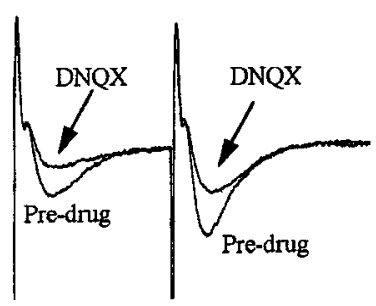

DHPG on the frequency and amplitude of spontaneous miniature IPSCs (mIPSCs) to differentiate between these possible mechanisms. If mGluRs act postsynaptically to reduce the effects of GABA, then one would expect to observe a decrease in the mean amplitude of mIPSCs. In contrast, if the reduction in IPSPs is mediated by a decreasc in the number of quanta of GABA released, then no effect on mIPSC amplitude would be observed. mIPSCs were recorded using whole-cell recordings from chloride-loaded CAl pyramidal cells in the presence of TTX (500 nM) and kynurenate ( $1 \mathrm{mM})$. Under these conditions, mIPSCs are inward currents when the cell is voltage clamped at -70 $\mathrm{mV}$. All spontaneous synaptic events recorded under these conditions were blocked by addition of the $\mathrm{GABA}_{\mathrm{A}}$ receptor antagonist, bicuculline (100 $\mu \mathrm{M}$; see Fig. 10). DHPG $(100 \mu \mathrm{M})$ had no significant effect on either the amplitude or the frequency of mIPSCs, consistent with a presynaptic site of action (Fig. 10). The mean ( \pm SEM) amplitude of mIPSCs recorded in the presence of DHPG was $102.4 \pm 8.7 \%$ of the predrug amplitude, and the frequency of mIPSCs was $99.8 \pm 10.8 \%$ of predrug values $(N=3)$. As mentioned above, mGluR activation reduces the amplitude of polysynaptic IPSPs by reducing excitatory synaptic transmission onto CA1 interneurons and by inhibiting GABAmediated transmission onto CA1 pyramidal cells (Desai et al., 1994). Thus, although L-AP4 does not reduce transmission at GABAergic synapses (as indicated by the lack of effect on monosynaptic IPSPs), it is possible that group III mGluRs could be involved in the reduction of polysynaptic IPSPs by virtue of their effects on excitatory synaptic transmission. We tested this hypothesis by determining the effect of the group-selective mGluR agonists on polysynaptic IPSPs in area CA1. Interestingly, while only DHPG was effective at reducing monosynaptic IPSPs, both DHPG (100 $\mu \mathrm{M})$ and L-AP4 (1 mM) reduced the amplitude of polysynaptically evoked IPSPs in area CAl (Fig. 11). The group II-selective agonist, DCG-IV (1 $\mu \mathrm{M})$, had no effect on polysynaptic IPSPs.

\section{Discussion}

The data presented here suggest that two distinct mGluR subtypes can serve as presynaptic autoreceptors involved in reducing glutamate release from Schaffer collateral terminals in area CA1 of the hippocampus. DHPG, a highly selective agonist for group I mGluRs, and L-AP4, a selective group III mGluR ag-

It is not yet known whether mGluR activation reduces transmission at inhibitory GABAergic synapses by a presynaptic or postsynaptic mechanism. Thus, we determined the effect of

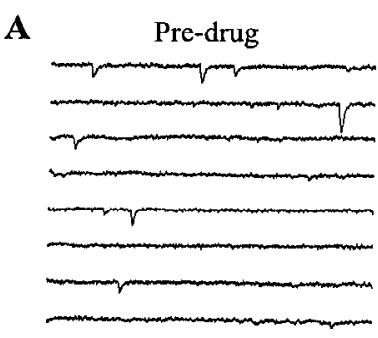

B

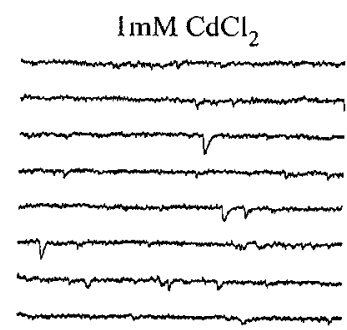

C

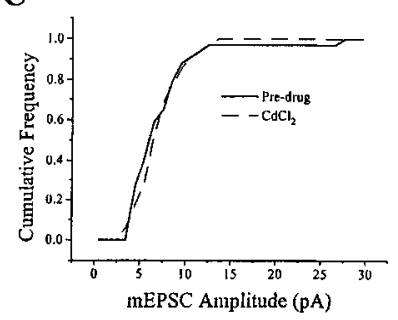

Figure 7. Blockade of voltage-sensitive calcium channels does not alter mEPSC frequency or amplitude. $A, B$, Continuous records recorded immediately prior to $(\Lambda)$ and after $6 \mathrm{~min}$ in the presence of $1 \mathrm{mM} \mathrm{CdCl} \mathrm{Cl}_{2}(B)$. Records are $1.5 \mathrm{sec}$ in duration and are separated by $40 \mathrm{pA}$. $C$, Cumulative frequency plot demonstrating the lack of effect of $\mathrm{CdCl}_{2}$ on mEPSC amplitude. $D$, Representative tEPSPS recorded immediately prior to addition of $\mathrm{CdCl}_{2}$ (control), after approximately $2 \mathrm{~min}$ in 1 $\mathrm{mM} \mathrm{CdCl}_{2}$, and after an extensive wash period. $E$, Mean ( \pm SEM) data from three experiments in each group showing the lack of effect of $\mathrm{CdCl}_{2}$ on mEPSC frequency and amplitude, and the complete blockade of evoked $\mathrm{f}$ EPSPs by $\mathrm{CdCl}_{2}$. 

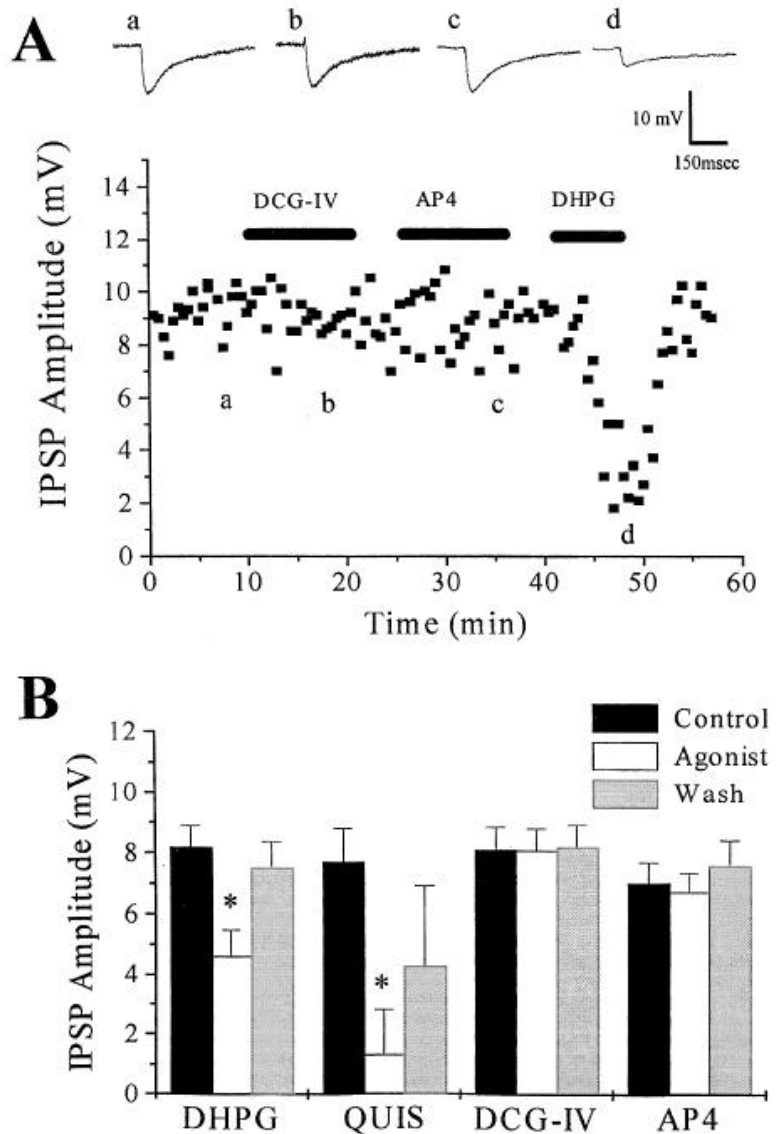

Figure 8. Group I, but not group II or group III, agonists reduce monosynaptically evoked IPSPs in area CA1. Monosynaptic IPSPs were recorded in the presence of $1 \mathrm{~mm}$ kynurenate to block fast glutamatergic transmission. $A$, Time course of a representative experiment showing the lack of effect of DCG-IV $(1 \mu \mathrm{M})$ and L-AP4 $(1 \mathrm{mM})$ and the reversible depression of monosynaptic IPSPs induced by DHPG (100 $\mu \mathrm{M}) . B$, Mean \pm SEM of five to seven experiments in each group showing the significant depression of monosynaptic IPSPs by the group I agonists DHPG $(100 \mu \mathrm{M})$ and quisqualate $(10 \mu \mathrm{M})$ and the lack of effect of DCG-IV $(1 \mu \mathrm{M})$ and D,L-AP4 $(1 \mathrm{~mm}) .{ }^{*} p<0.05$, ANOVA. The group labeled AP4 includes four experiments using $1 \mathrm{~mm} \mathrm{D,L-AP4}$ and two experiments using $1 \mathrm{~mm}$ L-AP4.

onist, both reduce transmission at the Schaffer collateral-CA1 synapse. Furthermore, depression of fEPSPs by DHPG was blocked by the mGluR $1 / 2$ antagonist, $(+)$ MCPG, whereas the depression of fEPSPs by L-AP4 was insensitive to (+)MCPG, suggesting that the responses to these two agonists are mediated by distinct mGluR subtypes. Finally, biophysical studies suggest that the effects of these two agonists are mediated by different mechanisms. Thus, L-AP4 induced a significant depression of mEPSC frequency, whereas DHPG had no effect on mEPSC frequency.

The present finding that L-AP4 can completely inhibit transmission at the Schaffer collateral-CA1 synapse in 30-40-d-old rats seems to be in contrast to the studies of Baskys and Malenka (1991), which show that the inhibition of transmission at this synapse by L-AP4 is developmentally downregulated and is virtually absent in rats aged over $30 \mathrm{~d}$. However, these studies only examined the effects of a single concentration $(50 \mu \mathrm{M})$ of L-AP4. Thus, the findings presented here may reflect a developmental decrease in the potency of L-AP4. There are several possible explanations for this finding. First, it is possible that
A Control

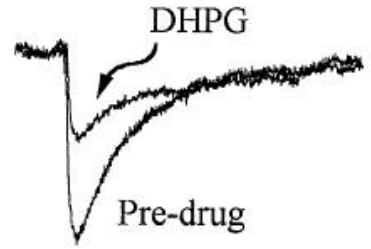

$(+) \mathrm{MCPG}$
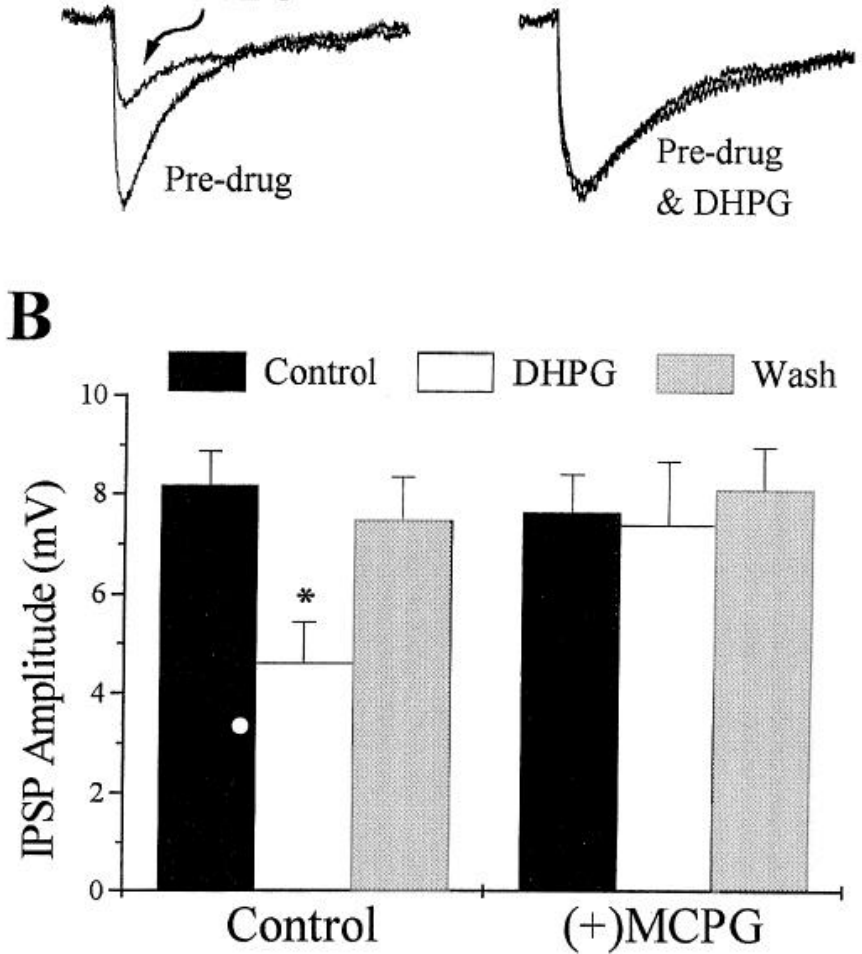

Figure 9. The depression of monosynaptic IPSPs by DHPG is blocked by (+)MCPG. A, Representative traces showing the depression of monosynaptic IPSPs by DHPG $(100 \mu \mathrm{M})$ under control conditions and in the presence of $500 \mu \mathrm{M}(+)$ MCPG. $B$, Mean \pm SEM data from five experiments in each condition. ${ }^{*} p<0.05$, ANOVA.

there is a developmental decrease in the receptor reserve, which would result in a decrease in the agonist potency. It is also possible that the predominant group III mGluR expressed in adult rats is different from that expressed in younger animals. For example, of the group III mGluRs expressed in rat hippocampus, L-AP4 activates mGluR4 much more potently than mGluR7 (see Suzdak et al., 1994, for review). Thus, it is possible that mGluR4 is more strongly expressed in Schaffer collateral terminals of younger animals, whereas mGluR7 is the predominant receptor in older rats. Future studies using quantitative immunoblotting should address this possibility.

Previous studies have demonstrated that L-AP4 also potently reduces transmission at mossy fiber-CA3 synapses in the guinea pig, but not the rat (Lanthorn et al., 1984). Our finding that L-AP4 decreases mEPSC frequency is in contrast to the effects of L-AP4 at mossy fiber-CA3 synapses in guinea pig, where L-AP4 reduces evoked EPSPs, but has no effect in the amplitude or frequency of miniature EPSPs (Cotman et al., 1986). Thus, it is likely that L-AP4-sensitive receptors decrease transmission at this synapse through a different mechanism than those at the rat Schaffer collateral-CA1 synapse.

As discussed above, DHPG is a highly selective agonist for the group I mGluRs (Ito et al., 1992; Schoepp et al., 1994; Gereau and Conn, 1995). Taken together with previous studies showing that quisqualate also reduces excitatory synaptic transmission at this synapse (Baskys and Malenka, 1991), these data suggest that a group I mGluR (mGluR1 or mGluR5) or a closely 
A Pre-drug

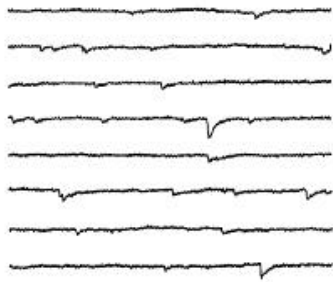

B

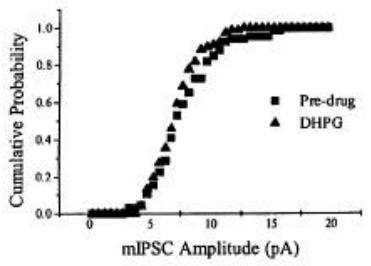

DHPG

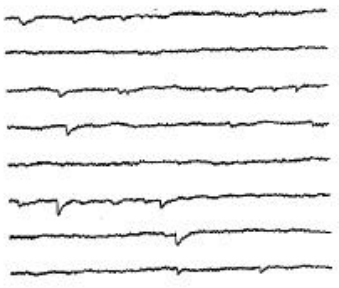

C

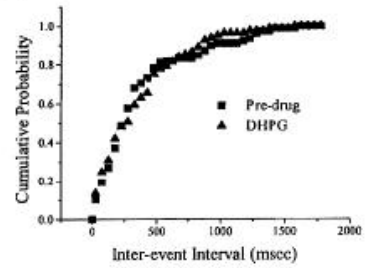

Bicuculline

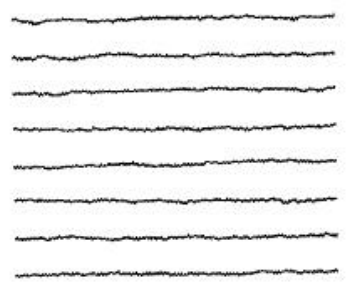

D

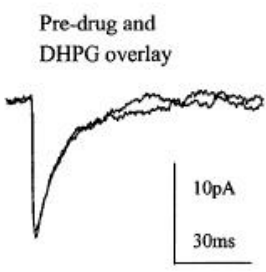

Figure 10. DHPG has no effect on the frequency or amplitude of spontaneous miniature IPSCs. mIPSCs were recorded from chloride-loaded CA1 pyramidal cells in the presence of TTX $(500 \mathrm{nM})$ and kynurenate $(1 \mathrm{~mm}) . A$, Sample traces recorded before (predrug) and after $10 \mathrm{~min}$ in DHPG (100 $\mu \mathrm{M})$, and after $2 \mathrm{~min}$ in bicuculline $(100 \mu \mathrm{M})$. Traces are $1.5 \mathrm{sec}$ in duration and are separated by $40 \mathrm{pA} . B$ and $C$, Cumulative frequency plots showing the lack of effect of DHPG on mIPSC amplitude $(B)$ and interevent interval (C) (Kolmogorov-Smirnov test; $p>$ $0.01)$. $D$, Overlayed averages of all mIPSCs recorded and shown in $B$ and $C$ demonstrating the lack of effect of DHPG on mIPSC amplitude and kinetics. Similar results were observed in three separate experiments. related receptor is likely to be involved in regulation of excitatory synaptic transmission at the Schaffer collateral-CA1 synapse. At present, it is not known which group I mGluR may be localized on Schaffer collateral terminals. Previous studies have shown that mGluR1a does not appear to be localized on excitatory or inhibitory nerve terminals in the hippocampus (Martin et al., 1992; Baude et al., 1993). However, the subcellular distribution patterns for the other mGluRl splice variants (mGluR1b/mGluR1c) are not yet known. Furthermore, the subcellular distribution pattern of mGluR5 has not yet been described. Thus, it is also possible that mGluR1b, mGluR1c, mGluR5, or an as of yet uncloned group I mGluR mediates this depression of EPSCs.

The finding that a group I mGluR can serve as a presynaptic autoreceptor is somewhat surprising since previous studies have suggested that group II and group III mGluRs are the predominant presynaptic mGluRs. However, a number of previous studies are consistent with the finding that group I mGluRs may also have a presynaptic role. For instance, previous studies have shown that mGluR activation decreases high voltage-activated calcium currents in a variety of neurons (Lester and Jahr, 1990; Swartz and Bean, 1992; Sahara and Westbrook, 1993; Swartz et al., 1993; Trombley and Westbrook, 1993; Stefani et al., 1994), and this has been suggested as a mechanism for mGluR-induced reduction of synaptic transmission. Interestingly, it has been shown that approximately $90 \%$ of hippocampal pyramidal cells in culture express 1S,3R-ACPD-induced inhibition of voltagesensitive calcium channels, whereas only about $10 \%$ of the pyramidal cells showed L-AP4-induced inhibition of calcium channel function (Sahara and Westbrook, 1993). Furthermore, quisqualate, a potent group I mGluR agonist, inhibits voltage sensitive calcium channels in hippocampal neurons (Lester and Jahr, 1990). Finally, the agonist rank order of potency for modulation of calcium channels in dissociated CA3 pyramidal cells is quisqualate $>$ glutamate $>$ ibotenate $>$ trans-ACPD, and this group reported that L-AP4 was not effective at inhibition voltage-gated calcium channels in these cells (Swartz and Bean, 1992). This rank order of potency is consistent with mediation by a group I mGluR, but not by a group II or group III mGluR (see Pin and Duvoisin, 1995). Thus, it is possible that group I mGluRs reduce synaptic transmission by inhibiting voltage-sensitive calcium channels. The present finding that DHPG has no effect on either frequency or amplitude of mEPSCs is consistent with this hypothesis. If DHPG is acting through this mechanism,
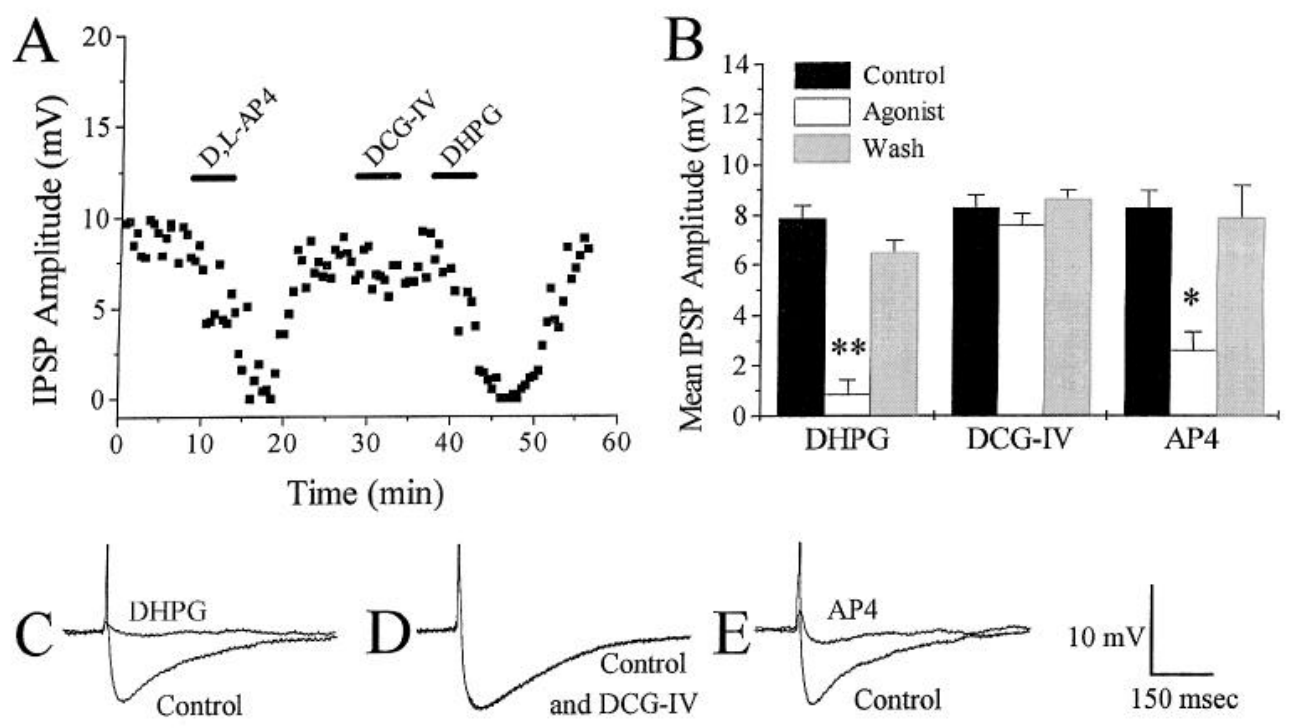

Figure 11. Both DHPG and L-AP4 reduce polysynaptically evoked IPSPs in area CA1. A, Time courese showing the depression of polysynapic IPSPs by both D,L-AP4 and DHPG, but not DCG-IV. Agonist applications were brief in this experiment for illustration purposes only to allow rapid washout of drug effects. $B$, Mean \pm SEM data showing the effects of $10 \mathrm{~min}$ applications of DHPG $(100 \mu \mathrm{M})$, DCG-IV $(1 \mu \mathrm{M})$ and D,L- or L-AP4 (1 mM). $N$ $=5-7$ for each drug. ${ }^{*} p<0.05$, ANOVA. ${ }^{* *} p<0.01$, ANOVA. $C-E$, Sample traces taken prior to agonist addition and after $10 \mathrm{~min}$ in the presence of the various agonists. 
one may not expect to observe a modulation of mEPSC frequency. Indeed, the present and previous studies have shown that blockade of voltage-sensitive calcium channels with cadmium, nifedipine, nimodipine or $\omega$-conotoxin do not decrease the basal frequency of mEPSCs in CA1 pyramidal cells (see Fig. 7 and Parfitt and Madison, 1993), but calcium channel blockers do inhibit synaptic transmission in area CAl (Fig. 7 and Luebke et al., 1993; Wheeler et al., 1994). Thus, while the exact mechanism by which DHPG decreases synaptic transmission at the Schaffer collateral-CA1 synapse is not known, our data suggest that DHPG may decrease action potential-dependent glutamate release by inhibiting voltage-sensitive calcium channel function. Future studies should directly address this possibility.

The present data and previous studies suggest that L-AP4 also reduces transmission at the Schaffer collateral-CA1 synapse by a presynaptic mechanism. As with DHPG, the precise mechanism by which L-AP4 acts is not yet known. However, it is interesting to note that L-AP4 may reduce synaptic transmission at this synapse by a mechanism that is independent of voltagedependent calcium channels. For instance, only about $10 \%$ hippocampal pyramidal neurons in culture possess L-AP4-sensitive receptors that modulate calcium channels (Sahara and Westbrook, 1993). Furthermore, as mentioned above, blockers of voltage-sensitive calcium channels do not decrease the basal frequency of mEPSCs in area CA1 (Fig. 7 and Parfitt and Madison, 1993). The present finding that L-AP4 reduces mEPSC frequency suggests that L-AP4-sensitive receptors localized on Schaffer collateral terminals may act to decrease glutamate release by inhibiting some other component of the glutamatc relcase process. Interestingly, we have recently performed immunocytochemistry studies in which we found that mGluR7 antibodies stained vericose and punctate fibers in the stratum radiatum of area CA1 (Bradley et al., 1995, submitted). This is consistent with the hypothesis that mGluR7 has a largely presynaptic localization in the area of Schaffer collateral terminals. However, immunocytochemistry studies at the electron microscopy level will be required to rigorously determine the pre- and postsynaptic localization of the group III mGluRs in the hippocampal formation.

Taken together with previous studies showing that activation of group II mGluRs can regulate excitatory (Lovinger and McCool, 1995) and inhibitory (Hayashi et al., 1993; Poncer and Miles, 1994) synaptic transmission, the present studies suggest that mGluRs belonging to all three groups can modulate synaptic transmission. This is in contrast to the receptors for other neuromodulatory transmitters such as norepinephrine, serotonin, adenosine, and others, for which only a relatively limited subset of the receptors are believed to serve as presynaptic autoreceptors. The fact that receptors from all mGluR groups can act to depress synaptic transmission speaks to the physiological importance of this phenomenon in brain function.

We also examined the mGluR subtypes involved in modulation of GABAergic transmission in CA1. We found that the selective group I mGluR agonist, DHPG, and the potent and relatively selective group I agonist, quisqualate, both reduced monosynaptic IPSPs in area CA1, whereas the group II-selective agonist, DCG-IV, and the group III-selective agonist, L-AP4, had no effect. The sensitivity of the mGluR that modulates GABAergic transmission in area CA1 to DHPG and quisqualate suggests that this receptor is likely a group I mGluR (mGluR1 or mGluR5). The sensitivity of this receptor to antagonism by $(+) \mathrm{MCPG}$ is also consistent with this hypothesis.
Although DHPG markedly reduced monosynaptic IPSPs, it had no effect on the amplitude or frequency of mIPSCs. This finding is consisitent with a presynaptic site of action. Calcium channel inhibition has been proposed as a mechamism for mGluR-mediated depression of GABAergic transmission in the striatum, based on the finding that trans-ACPD reduced the amplitude of high voltage-activated calcium currents and depressed GABA-mediated synaptic potentials with similar potency (Stefani et al., 1994). However, it is important to note that previous studies suggest that mGluR activation can induce large inward currents or depolarization in oriens/alveus interneurons in the hippocampus (Miles and Poncer, 1993; McBain et al., 1994) This could reduce the amplitude of evoked IPSPs by inducing a depolarization block of action potential generation. The present results cannot discriminate between inhihition of GABA release from presynaptic terminals and a depolarization block of action potential generation or propagation.

It is interesting that both DHPG and L-AP4 reduced polysynaptically evoked IPSPs in area CA1, whereas only DHPG reduced monosynaptically evoked IPSPs. Since L-AP4 does not reduce transmission at GABAergic synapses, it is likely that reduction of polysynaptic IPSPs by L-AP4 is due to reduced transmission at excitatory synapses onto inhibitory interneurons, as described by Desai et al (1994).

In conclusion, we have provided evidence that at least two distinct mGluR subtypes, one with a group I-like pharmacology and one with a group III-like pharmacology, are involved in mGluR-mediated depression of excitatory synaptic transmission at the Schaffer collatcral-CA1 synapsc. Analysis of mEPSCs and paired-pulse facilitation suggests that both receptors are localized presynaptically, but that they may regulate transmission through different mechanisms. In addition, a group I-like mGluR localized on GABAergic nerve terminals may regulate inhibitory synaptic transmission in area CA1. In future studies, it will be important to determine the precise mechanisms involved in the modulation of excitatory and inhibitory synaptic transmission by group I mGluRs and the specific mGluR subtypes within groups I and III that mediate these responses.

\section{References}

Baskys A, Malenka RC (1991) Agonists at metabotropic glutamate receptors presynaptically inhibit EPSCs in neonatal rat hippocampus. J Physiol (Lond) 444:687-701.

Baude A, Nusser Z, Roberts JDB, Mulvihill E, McIlhinney RAJ, Somogyi P (1993) The metabotropic glutamate receptor (mGluRl $\alpha$ ) is concentrated at perisynaptic membrane of neuronal subpopulations as detected by immunogold reaction. Neuron 11:771-787.

Blanton MG, LeTurco JJ, Kriegstein AR (1989) Whole-cell recording from neurons in slices of reptilian and mammalian cerebral cortex. $J$ Neurosci Methods 30:203-210.

Bradley SR, Levey AI, Conn PJ (1995) Immunocytochemical localization of group III metabotropic glutamate receptors in the hippocampus with subtype-specific antibodies. (submitted).

Chinestra P, Aniksztejn L, Diabira D, Ben-Ari Y (1993) (RS)- $\alpha$-methyl-4- carboxyphenylglycine neither prevents induction of LTP nor antagonizes metabotropic glutamate receptors in CAl hippocampal neurons. J Neurophysiol 70:2684-2689.

Cotman CW, Flatman JA, Ganong AH, Perkins MN (1986) Effects of excitatory amino acid antagonists on evoked and spontaneous excitatory potentials in guinea-pig hippocampus. J Physiol (Lond) 378: 403-415.

Desai MA, Conn PJ (1991) Excitatory effects of ACPD receptor activation in the hippocampus are mediated by direct effects on pyramidal cells and blockade of synaptic inhibition. J Neurophysiol 66: 40-52.

Desai MA, Sinith TS, Conn PJ (1992) Multiple metabotropic glutamate receptors regulate hippocampal function. Synapse 12(3):206-213. 
Desai MA, McBain CJ, Kauer JA, Conn PJ (1994) Metabotropic glutamate receptor-induced disinhibition is mediated by reduced transmission at excitatory synapses onto interneurons and inhibitory synapses onto pyramidal cells. Neurosci Lett 181:78-82.

Evans RH, Francis AA, Jones AW, Smith DAS, Watkins JC (1982) The effects of a series of $\omega$-phosphonic and $\alpha$-carboxylic amino acids on electrically evoked and excitant amino acid-induced responses in isolated spinal cord preparations. Br J Pharmacol 75:65-75.

Gereau RW, Conn PJ (1995) Roles of specific metabotropic glutamate receptor subtypes in regulating hippocampal CA1 pyramidal cell excitability. J Neurophysiol, in press.

Glaum SR, Miller RJ (1994) Acute regulation of synaptic transmission by metabotropic glutamate receptors. In: The metabotropic glutamate receptors (Conn PJ, Patel J, eds), pp 147-172. Totowa, NJ: Humana.

Hayashi Y, Momiyama A, Takahashi T, Ohishi H, Ogawa-Meguro R, Shigemoto R, Mizuno N, Nakanishi S (1993) Role of a metabotropic glutamate receptor in synaptic modulation in the accessory olfactory bulb. Nature 366:687-690.

Hayashi Y, Sekiyama N, Nakanishi S, Jane D, Sunter DC, Birse EF, Udvarhelyi PM, Watkins JC (1994) Analysis of agonist and antagonist activities of phenylglycine derivatives for different cloned metabotropic glutamate receptor subtypes. J Neurosci 14:3370-3377.

Ito I, Kohda A, Tanabe S, Hirose E, Hayashi M, Mitsunaga S, Sugiyama H (1992) 3,5-Dihydroxyphenylglycine: a potent agonist of metabotropic glutamate receptors. Neuroreport 3:1013-1016.

Lanthorn TH, Ganong AH, Cotman CW (1984) 2-Amino-4-phosphonobutyrate selectively blocks mossy fiber-CA3 responses in guinea pig but not rat hippocampus. Brain Res 290:174-178.

Liu Y-B, Disterhoft JF, Slater NT (1993) Activation of metabotropic glutamate receptors induces long-term depression of GABAergic inhibition in the hippocampus. J Neurophysiol 69:1000-1004.

Lovinger DM, McCool BA (1995) Metabotropic glutamate receptormediated presynaptic depression at corticostriatal synapses involves mGluR2 or 3. J Neurophysiol 73:1076-1083.

Luebke JI, Dunlap K, Turner TJ (1993) Multiple calcium channel types control glutamatergic synaptic transmission in the hippocampus. Neuron 11:895-902.

Martin LJ, Blackstone CD. Huganir RL, Price DL (1992) Cellular localization of a metabotropic glutamate receptor in rat brain. Neuron 9:259-270.

McBain CJ, DiChiara TJ, Kauer JA (1994) Activation of metabotropic glutamate receptors differentially affects two classes of hippocampal interneurons and potentiates excitatory synaptic transmission. J Neurosci 14:4433-4445.

Miles RM, Poncer JC (1993) Metabotropic glutamate receptors mediate a post-tetanic excitation of guinea-pig hippocampal inhibitory neurones. J Physiol (Lond) 463:461-473.

Pacelli GJ, Kelso SR (1991) Trans-ACPD reduces multiple compo- nents of synaptic transmission in the rat hippocampus. Neurosci Lett 132:267-269.

Parfitt KD, Madison DV (1993) Phorbol esters enhance synaptic transmission by a presynaptic, calcium-dependent mechanism in rat hippocampus. J Physiol (Lond) 471:245-268.

Pin J-P, Duvoisin R (1994) The metabotropic glutamate receptors: structure and function. Neuropharmacology 34:1-26.

Poncer JC, Miles R (1994) Dual modulation of synaptic inhibition by metabotropic glutamate receptors in the rat hippocampus. Soc Neurosci Abstr 20:487.

Sahara Y, Westbrook GL (1993) Modulation of calcium currents by a metabotropic glutamate receptor involves fast and slow kinetic components in cultured hippocampal neurons. J Neurosci 13:3041-3050.

Salt TE, Eaton SA (1995) Distinct presynaptic metabortopic receptors for L-AP4 and CCG1 on GABAergic terminals: pharmacological evidence using novel methyl derivative mGluR antagonists, MAP4 and MCCG, in the rat thalamus in vivo. Neuroscience 65:5-13.

Saugstad JA, Kinzie JM, Mulvihill ER, Segerson TP, Westbrook GL (1994) Cloning and expression of a new member of the L-2-amino4- phosphonobutyric acid-sensitive class of metabotropic glutamate receptors. Mol Pharmacol 45:367-372.

Schoepp DD, Goldsworthy J, Johnson BG, Salhoff CR, Baker SR (1994) 3,5-Dihydroxyphenylglycine is a highly selective agonist for phosphoinositide hydrolysis-linked metabotropic glutamate receptors in the rat hippocampus. J Neurochem 63:769-772.

Stefani A, Pisani A, Mercuri N, Bernardi G, Calabresi P (1994) Activation of metabotropic glutamate receptors inhibits calcium currents and GABA-mediated synaptic potentials in striatal neurons. $J$ Neurosei 14:6734-6743.

Suzdak PD, Thomsen, C, Mulvihill, E, Kristensen P (1994) Molecular cloning, expression and characterization of metabotropic glutamate receptor subtypes. In: The metabotropic glutamate receptors (Conn PJ, Patel J, eds), pp 1-30. Totowa, NJ: Humana.

Swartz KJ, Bean BP (1992) Inhibition of calcium channels in rat CA3 pyramidal neurons by a metabotropic glutamate receptor. J Neurosci 12:4358-4371.

Swartz KJ, Merritt A, Bean BP, Lovinger DM (1993) Protein kinase C modulates glutamate receptor inhibition of $\mathrm{Ca}^{++}$channels and synaptic transmission. Nature 361:165-168.

Trombley PQ, Westbrook GL (1992) L-AP4 inhibits calcium currents and synaptic transmission via a G-protein-coupled glutamate receptor. J Neurosci 12:2043-2050.

Watkins J, Collingridge G (1994) Phenylglycine derivatives as antagonists of metabotropic glutamate receptors. Trends Pharmacol Sci 15 : 333-342.

Wheeler DB, Randall A, Tsien RW (1994) Roles of N-type and Q-type $\mathrm{CA}^{2+}$ channels in supporting hippocampal synaptic transmission. Science 264:107-111. 